\title{
Erratum to: Digital Enterprise Challenges
}

\author{
George L. Kovács ${ }^{1}$, Peter Bertók ${ }^{2}$, and Géza Haidegger ${ }^{1}$ \\ 1 Computer and Automation Institute, Hungary \\ 2 School of Computer Science and Information Technology, RMIT University, \\ Australia
}

\section{Erratum to: \\ G.L. Kovács et al. (Eds.) \\ Digital Enterprise Challenges \\ DOI: $10.1007 / 978-0-387-35492-7$}

The book was inadvertently published with an incorrect name of the copyright holder. The name of the copyright holder for this book is: (c) IFIP International Federation for Information Processing. The book has been updated with the changes.

The updated original online version for this book can be found at DOI: 10.1007/978-0-387-35492-7 